\title{
Cidadania democrática e inserção política das mulheres
}

O intuito deste texto é refletir brevemente sobre uma das chaves analíticas envolvidas no debate sobre democracia e gênero, a cidadania. Como chaves analíticas, podem ser compreendidos alguns conceitos e categorias que compõem o "pacote" do debate democrático moderno. Estas, incorporadas historicamente como prática e como horizonte político emancipatório, formaram-se com e na modernidade, consolidando-se como requisitos e mesmo pressupostos políticos. Atualmente, pode-se sugerir, conformam uma espécie de ethos contemporâneo sobre a justiça democrática. Tal ethos, de certo modo, reflete a disseminação e a ampliação de projetos e de valores até há pouco compartilhados apenas por ideários políticos específicos ou por grupos determinados.

A cidadania, foco central deste artigo, aparece como um desses casos; talvez um dos mais centrais, conforme sugere Magnette (2005). Ela se articula com outras quatro problemáticas, aqui só tangencialmente mencionadas, embora estruturantes desse processo. ${ }^{1}$ É reconhecido, porém, que o leque contemporâneo é bem mais abrangente e, a depender da perspectiva, envolve

* É professora do Departamento de Ciências Sociais da Universidade Estadual do Rio de Janeiro (Rio de Janeiro, RJ). E-mail: claramaria.araujo@gmail.com.

Vários autores que serviram de referência para este paper compartilham de uma perspectiva mais interdisciplinar mesmo quando estão focando a dimensão política, sociológica ou filosófica. Embora sejam de campos e tradições analíticas diferentes, eles se propõem a acionar ou se apoiam na dimensão sociológica. Preocupam-se com o excesso da dimensão normativa que atualmente domina muitos dos debates fora do direito ou da filosofia política. Entre esses autores, destacam-se, por exemplo: Rosanvallon (2010); Hayward e Lukes (2008); Fraser (2003, 2007); Sen (2009); Lister (2007); Dietz (2000); e Turner (1990, 2007). 
uma miríade de novas categorias. Como esse leque não é o objeto desta reflexão, será indicado basicamente um conjunto mais restrito que o compõe.

Neste texto, preliminarmente são feitas algumas considerazões gerais sobre estas dimensões: a cidadania e as tensões presentes na democracia contemporânea. Em seguida, pretende-se retomar algumas das incongruências constitutivas do sujeito-ator-cidadão quando pensado na perspectiva de gênero e, sobretudo, no seu pressuposto de se viabilizar como recurso legítimo da democracia representativa. Com isso, torna-se possível retomar e pensar sobre tensões constitutivas da cidadania na perspectiva de gênero. Por fim, é apresentada de forma breve uma alternativa discutida pela literatura. Ao fazê-lo, pretende-se unicamente acrescentar dimensões para esse debate, e não propriamente indicar essas dimensões como caminhos efetivos a seguir.

Cabe dizer ainda que, embora se trate de uma reflexão teórica, o intuito é também fornecer elementos da e para a dimensão da prática política democrática na perspectiva de gênero. Apesar dos limites a serem destacados mais adiante, comunga-se, aqui, com a compreensão de que "mulheres são implicitamente parte do conceito de democracia, do mesmo modo que foram implicitamente parte do conceito de 'cidadão'”. (Paxton, 2008, p. 67). ${ }^{2}$

\section{Algumas considerações sobre o tema da democracia vis-à-vis o da cidadania}

Para cada problemática que se articula à cidadania, implica-se considerar as tensões que são inerentes à sua própria constituição como dimensão normativa e como objeto da prática sociopolítica, bem como aquelas que a elas se somaram e foram originadas pelas transformações e diversificações da vida social nos dois últimos séculos. Como foi dito, aqui cabem só os registros de tais dimensões. Assim, pode-se destacar a constituição da esfera pública como esfera separada e legítima para a realização e a viabilização da política. Desse modo, a incorporação política e empírica da cidadania se viabiliza(ria) na figura do ator-chave, o cidadão, propriedade em sua pessoa, e na criação de uma esfera pública. Essa esfera seria paralela ao ambiente da vida privada/ cotidiana em alguns sentidos e oposta em outros, já que, como espaço de comunicação e de decisões, a esfera pública seria capaz de transcender interesses particulares ou paroquiais da vida privada em suas particularidades e, ao mesmo tempo, (supostamente) desprovida desses interesses.

Tradução livre. Perspectiva semelhante pode ser observada em Goertz e Mazur (2008). 
Um aspecto mais recente $\mathrm{a}$ acrescentar diz respeito à diversidade de atores contemporâneos e ao caráter dinâmico das demandas dirigidas a essa esfera (Habermas, 1987; Pateman, 1983, 1989; Fraser, 2003). Como segunda chave, podem ser citadas a centralidade e as condições de viabilidade dos princípios da representação política, prática que toma esse cidadão como mediador por excelência. Entre outros aspectos, o debate se propõe a discutir quem representa, o que deve ser representado e em quais espaços deve ocorrer a representação - ponto esse extremamente debatido a partir da dinamização da globalização, com o trânsito de pessoas entre países e suas novas possibilidades de cidadania. Há, também, os tipos de relação entre representantes e representados, sobretudo em se tratando da accountability. Como terceiro item, pode ser mencionado ainda o aspecto do ativismo cívico, assim como os caminhos e as razões da participação política, nas suas variadas formas, concebida a partir de distintas perspectivas, muitas vezes, inclusive, como espaço por excelência da participação cidadã, em contraposição à presença no âmbito da representação. ${ }^{3}$ Entre outros tópicos, discutem-se, atualmente, a diversidade existente nos atores e nos espaços desse ativismo e, ainda, os caminhos possíveis para vinculá-lo à dimensão da accountability, no caso da relação com a representação.

Norteando todas essas temáticas, esta última questão é muito debatida, porque, uma vez transformada em horizonte de realização dos itens anteriores, faz com que se encontrem o tema e o ideário da justiça, suas formas de viabilidade e o alargamento de suas fronteiras. Entre algumas outras e mais recentes dimensões, podem ser lembradas ainda as questões da equidade, da diversidade, das identidades políticas e dos direitos humanos. O conceito de cidadania se relaciona e só se viabiliza com essas dimensões e, ainda, com o debate sobre direitos, liberdade, igualdade social e julgamento político (Voet, 1988); e diz respeito, entre outros aspectos, à sua natureza ou ao que o conforma como sentido, aos tipos ideais e políticos de sua configuração, relativos aos atores que o constituíram e o constituem, aos pertencimentos que por eles perpassam, às noções e trajetórias dos direitos, bem como ao caráter dinâmico - voluntário ou involuntário - dos deslocamentos individuais e coletivos nos espaços sociais (migrações, sobretudo).

Tais transformações, novos ideários e novas modalidades de conflitos foram crescentemente pautados pela crítica ou pelo registro das desigual-

Sobre as distintas tradições da ação política e seus significados para a cidadania, ver Isin e Turner (2007). 
dades como o lado obscuro da democracia e a referência para a justiça. Os experimentos democráticos ocorrem em configurações sociais marcadas por desigualdades de recursos e de acesso, tanto econômico como cultural e político, envolvendo distintas clivagens (Therborn, 2006; Bourdieu, 1989; Sen, 2009). Talvez por seu papel crucial na própria constituição da democracia representativa, a explicitação da problemática por meio da demanda ou da denúncia via cidadania pode ser considerada como um exemplar privilegiado desse percurso. Com isso, muitas categorias têm sido postas em questão, sobre se são viáveis politicamente, e não apenas como incompletas. De todo modo, comunga-se aqui com as reflexões de Isin e Turner, para quem "a cidadania permanece importante como domínio ativo da democracia e como a principal expressão da política como pertencimento" e "coincide com a vitalidade e a importância como instituição legal e como experiência vivida" (2007, p. 14). ${ }^{4}$ Por se constituir em experiência vivida e, ao mesmo tempo, em práticas legitimadas institucionalmente, essa vitalidade é inerentemente geradora de tensão e de novas reflexões.

Um primeiro componente, que guarda certas tensões, pode ser definido como aquele que diz sobre a natureza própria da cidadania e que atinge seu primeiro sentido, ou sentido de origem, o da mediação e da relação entre direitos e obrigações. Analiticamente, as definições mais abrangentes identificam distintas dimensões e consideram três elementos como básicos na sua conformação conceitual, assim como na sua incorporação como categoria política. São eles: pertencimento, participação e direitos e responsabilidades (Turner, 1990, 1991; Lister et al., 2007; Siim, 2000; Voet, 1988). Como direitos, cidadania se refere ao status do indivíduo na sociedade - se este for adulto ou criança, terá diferentes direitos políticos, por exemplo. E é a referência aos direitos que vai se constituindo como predominante a partir do século XIX e marca o século XX (Lister, 2003; Turner, 1990, 1990).

Vários aspectos da moderna organização da vida social foram normatizados a partir de lutas e de demandas coletivas. Isso tende a associar esse deslocamento em direção aos direitos como algo que remete, automaticamente, a princípios mais equitativos. O problema é que, analiticamente, os direitos "tanto podem remeter a privilégios, definidos a partir de cima, como podem expressar o resultado de lutas radicais de grupos subordinados

4 Tradução livre. 
em torno de demandas e benefícios" (Turner, 1990, p. 209). Como se nota, não necessariamente a ideia de direitos remete a princípios igualitários ou participativos. Direitos sobre o quê? Direitos de quem? E direitos organizados por quem? Essas perguntas definem, também, o sentido que os direitos adquirem e o valor que eles assumem socialmente. Esse primeiro ponto é, sem dúvida, central para a compreensão da trajetória histórica das mulheres frente, sobretudo, mas não só, à cidadania política (Turner, 1990).

Cidadania é, também, uma categoria pensada, hoje, predominantemente a partir de um vetor: o inclusivo. Normalmente, tendemos a associar o termo a um sentido positivo e à ideia de inclusão. Como categoria política, a cidadania vem impregnada desse valor. No entanto, como categoria analítica e como reflexão teórica, nem sempre tais valores podem ser assim associados.

As análises empíricas dos processos sugerem a necessidade de observar, simultaneamente, dois movimentos: o da inclusão e o da exclusão. O próprio recorte que define a condição geral de cidadão, o estado-nação, já se constitui também como exclusão - exclusão dos que não pertencem originalmente a esse espaço, por exemplo. ${ }^{5}$ Em outros termos, o modo como essa categoria ou dimensão se construiu tem produzido formas contraditórias, mesmo antinômicas, nos experimentos da democracia representativa. Ao mesmo tempo, reconfigurações nessa trajetória colocaram outras formas de sujeitos e outros loci como elementos emergentes relevantes situados no campo do que concebemos ou pensamos como cidadania. Cabe, então, observar o seu caráter reflexivo na democracia moderna, pois "o caráter vacilante da democracia participa de sua própria essência, e não é uma simples incerteza prática" (Rosanvallon, 2010, p. 88).

Há, aqui, um caminho profícuo para pensar a ausência/presença das mulheres e sua agência para exercer a soberania, uma vez que, numa perspectiva mais pragmática de horizontes políticos de curto prazo, a ideia de processo nos possibilita construir estratégias de ação e de intervenção na política tal como ela é. A análise da trajetória da cidadania como uma dimensão possibilita, assim, a saída analítica de considerar a característica inerentemente processual da democracia e as possibilidades e potencialidades da cidadania nesse contexto.

Esse dado, atualmente, evoca a exclusão como problema para parcelas cada vez mais amplas de indivíduos e de grupos que migram e se deslocam entre e as fronteiras da nação. E põe em xeque a cidadania como forma de pertencimento. 
A característica processual surge, portanto, como premissa para pontuar e discutir, ainda que brevemente, as dimensões implicadas no conceito. Pensar a cidadania nessa perspectiva proposta para a democracia faz sentido desde que se comungue da leitura de Magnette (2005, p. 2) de que se trata do "principal instrumento ou ferramenta da legitimidade politica moderna [...] e se constitui num sitio privilegiado do link moderno da relação entre direito político e obrigacão política”. Isso é muito importante em se tratando das mulheres, do seu lugar e do seu não lugar, tanto na formulação moderna dos requisitos da e para a cidadania como nas formas de inserção atuais.

Em síntese, propõe-se considerar os limites e os déficits da cidadania na sua interseção com os déficits democráticos, tomando como referência a democracia como "processo inerentemente inacabado, como um projeto reflexivo e produtor de antinomias sempre geradoras de conflitos" (Rosanvallon, 2010, p. 74). Pode-se sugerir, então, que a história da cidadania e dos contextos nos quais ela foi construída, evocada ou negada é, intrinsecamente, a história da constituição dos sujeitos; e é também a história das mulheres como sujeitos ou da negação dessa condição, em muitos momentos. Rosanvallon nos fornece, portanto, algumas pistas para pensar a cidadania das mulheres como exclusão, inclusão e reconstrução de padrões de inserção política.

De fato, o termo cidadania adquiriu um sentido praticamente consensual e autoevidente na sociedade contemporânea. Falamos de cidadania como premissa de direitos, intrínseca à própria existência individual e coletiva. A expressão cidadania das mulheres - em razão das desigualdades estruturais a que estas foram historicamente submetidas - se tornou praticamente um mantra ao qual se recorre para salientar desigualdades e desvantagens, demandar direitos, pensar e propor políticas públicas. Mas, como assinala Duhn (apud Magnette 2005, p. 2), embora o tomemos como algo comum e consensual, o termo não é assim tão evidente e os caminhos por onde se pensa a cidadania implicam a postulação de perguntas essenciais para o indivíduo. Pergunta o autor:

O que significa ser um cidadão? Quem deve ser cidadão e onde? Como ele tem viajado desde então? O que esse aparecimento ou esse desaparecimento de fato significa? Em que a cidadania de fato consiste? (Duhn apud Magnette, 2005, p. 2). 
O sujeito mesmo da democracia, o cidadão, só se viabiliza num coletivo denominado de povo. Mas este só existe por meio das representações aproximativas e sucessivas de si mesmo. Há relações conflituosas com a definição do nós. “Quem é cidadão?", também perguntam Isin e Turner (2007, p. 15). Com isso, há que pensar sobre os desafios colocados para a cidadania em dimensões antes não consideradas; e, no debate atual, devem-se incorporar questões como as da diversidade e da diferença como requisitos dos experimentos democráticos justos, conforme têm assinalado vários autores (Benhabib, 2004; Isin e Turner, 2007; Lister, 2003).

Mas registrar e resgatar o caráter ambíguo da cidadania não necessariamente implica um desdobramento dual, um movimento do tipo ou ou: ou a cidadania é criticada como categoria pouco viável, e até eventualmente descartada; ou, ao contrário, passa a ser abraçada sem crítica, como a síntese do nosso ideário moderno de justiça. Ou é essencialmente um legado positivo, neutro e inclusivo; ou, então, é um legado masculino e excludente, a ser evitado ou descartado, conforme tendeu a acontecer em período recente. ${ }^{6}$ Tudo indica que as contradições constitutivas de sua natureza não impossibilitam uma crítica da exclusão e uma ação ativa pró-inclusão, tanto como análise teórica como também na condição de categoria da prática política que orienta demandas por direitos e agregações.

\section{Cidadania e gênero: incongruências, tensões e caminhos alternativos}

Como já se discutiu (Araújo, 1999), o advento da modernidade foi marcado por ambiguidades sobre o sentido do humano e seu vínculo com a definição de cidadão. De início, legitimou uma exclusão de parte desses indivíduos - mulheres, em particular. Ao criar os seus princípios políticos, as duas grandes revoluções ${ }^{7}$ formularam ou reproduziram o princípio da diferença entre os sexos já encontrado anteriormente (Duby e Perrot, 1994; Coole, 1998). Seja por algum tipo de justificativa moral ou sustentado em uma prerrogativa mais pragmática, as mulheres estiveram excluídas das experiências ocidentais que serviram de base para a constituição da cidadania moderna. Para tanto, discursos retóricos trataram de criar um conjunto de regras que se destacavam discursivamente. Elas foram calcadas em estraté-

6 Vários autores terminam por colocar esse dilema ao discutirem as ambiguidades dessa categoria. Ver, por exemplo, Riot-Sarcey $(2006,2009)$ ou Turner $(1990,1991)$.

Americana e francesa. 
gias de valorizações, injunções e proibições voltadas para sustentar e moldar determinada identidade feminina, incongruente com as dinâmicas da esfera pública, sobretudo a política (Riot-Sarcey, 1995, 2009).

O peso simbólico do discurso da diferença e dos lugares naturalmente apropriados para cada sexo foi fundamental na construção da ordem moderna e na aceitação da não cidadania das mulheres, sem, contudo, excluí-las da sua condição humana. A saída para incluí-las, já que elas não estavam fora da humanidade, foi a distinção entre o sujeito passivo vinculado à esfera privada e desprovido de certos requisitos para interferir na coisa pública - e o sujeito ativo, cidadão e dotado desses requisitos. Tal foi a força dessa construção simbólica que não foram necessárias mais evidências empíricas para justificar a não cidadania das mulheres no corpo político (Riot-Sarcey, 2006), embora estivessem incluídas na categoria dos humanos.

Contudo, esses impactos se tornam um duplo complicador para o acesso das mulheres à esfera pública e, particularmente, à representação. Primeiro, o princípio inerente de uma exclusão, antes mesmo de incluir aqueles considerados cidadãos. Segundo, a derivação objetiva e simbólica dessa negativa. A realização da representação requer uma seleção que é, em si, uma exclusão prévia: aqueles que podem e/ou querem se habilitar a tentar o acesso à representação. Trata-se da ideia de representação como universo reduzido ou extração/expressão desse universo, cuja base moderna foi a nação (Urbinati, 2006; Rosanavallon, 2010). Mas, como foi visto, independentemente dos problemas contemporâneos, a representação constitui, em si, um paradoxo - paradoxo da escolha da representação e de sua possibilidade, pois esta só se realiza com candidaturas prévias, portanto "uma seleção anterior ao próprio exercício da soberania do cidadão".

$\mathrm{Na}$ democracia representativa, como processo democrático, podemos pensar que as mulheres enfrentam uma desvantagem dupla: a exclusão formal inicial da cidadania, derivando posicionamento efetivamente desvantajoso; e a exclusão atual, que denomino de exclusão estendida. Estendida porque muitos de seus efeitos e aspectos se originam indiretamente e não mais formal e diretamente dessa exclusão de base. O paradoxo as atingiria, assim, como um duplo no Ocidente e/ou nos modelos de democracia representativa: não mais de forma normativa, mas, tomando a ideia de Sen (2009), pelas suas "capacidades de realizações efetivas". 
A exclusão da mulher da cena pública não é sinônimo de sua ausência da cena social. Ao contrário, como ressalta a literatura de referência usada neste texto, há sua inclusão nessa cena como sustentáculo da política na esfera pública. Nesse caso, uma base forte seria a (artificial) dualidade de esferas e sua correspondência com naturezas, além dos atributos de sexo que sustentam a viabilização da cidadania política. Assim, para que a cidadania pudesse ser exercida pelos homens ${ }^{8}$, o desenho e as dinâmicas construídas para o seu exercício pressupunham a contribuição das mulheres como parte da comunidade dos indivíduos. As dicotomias conferiam atributos próprios ou associados a cada sexo, os quais sustentariam as praticas cidadãs e não cidadãs, e legitimariam os lugares de homens e mulheres. Essa dicotomia se estrutura e, de certa forma, subsiste como habitus (Bourdieu, 1989), incorporada nos atributos ou disposições como inerentes, conforme sistematizado por Siim na comparação abaixo:

Quadro 1: Atributos e disposições inerentes a homens e a mulheres para a viabilização da cidadania política

\begin{tabular}{c|c}
\hline Homem: público e cidadão & Mulher: privada e não cidadã \\
\hline Abstrato, descorporificado, mental. & Particular, corporificada e sustentada na natureza. \\
\hline $\begin{array}{c}\text { Racional, habilitado a atuar de forma } \\
\text { desapaixonada e com padrões de justiça. }\end{array}$ & $\begin{array}{c}\text { Emocional, irracional, sujeita ao desejo e à } \\
\text { paixão, inábil para atuar de forma justa. }\end{array}$ \\
\hline Imparcial, preocupado com & $\begin{array}{c}\text { Parcial, preocupada com o privado e com } \\
\text { questões domesticas (menores). }\end{array}$ \\
o interesse público. & Dependente, passiva e fraca. \\
\hline Independente, ativo, heroico e forte. & Mantém-se no reino da necessidade, \\
do natural e do repetitivo.
\end{tabular}

Fonte: $\operatorname{Siim}(2000$, p. 71)

Como é possível notar, ao lado dessa tensão que transcende um único recorte e organiza a própria ideia de agente e sujeito, o constructo da cidadania foi, simultaneamente, um conjunto de dicotomias associadas ao gênero, fundamentais para justificar sua exclusão, mas estruturantes do princípio essencial (natural) de esfera pública democrática.

Com isso, para além de saber o que significa ou quem é o cidadão, bem como de responder às demais perguntas postas acima, no caso das mulheres,

Sobre isso, um exemplo dos mais ricos pode ser encontrado no romance Emilio, de Rousseau. 
há um complicador de base. Como sugere Lister, a questão é a de saber em que medida um conceito originalmente construído com base na exclusão das mulheres pode ser reformulado de maneira satisfatória para "incluir as mulheres, mais do que simplesmente acrescentá-las" (2003, p. 88, grifo meu). E, em sendo possível tal feito, como, ao mesmo tempo, garantir pleno reconhecimento de suas diferentes e mutantes identidades? Um ideário plenamente democrático implicaria inclusão equitativa das mulheres. Mas, para muitos autores, a cidadania parece não responder de fato a essa inclusão por um erro de origem.

Nos processos eleitorais, podemos pensar, por exemplo, nas suas inclusões como candidatas, sistematicamente menores em comparação com os homens, derivadas justamente desse processo - ou seja, nas capacidades socialmente construídas, que determinam de antemão as disposições subjetivas, além de objetivas, de mulheres para disputar e participar da representação (Bourdieu, 1989; Matland, 2002). Vale notar que as cotas eleitorais inclusive vieram, em parte, dessa perspectiva.

Contudo, alguns caminhos e exercícios podem ser pensados antes de descartar a cidadania por seu erro de origem. Antes de introduzir um caminho possível, proposto na literatura, convém chamar atenção para outro ponto de tensão. Para além desses contextos históricos e dos processos imediatos de demanda por mais efetividade da democracia, a relação do feminismo com a cidadania tem sido ambivalente (Siim, 2000). Um dos aspectos dessa ambivalência remete às diferentes bases e visões feministas sobre a cidadania igual e completa das mulheres. Nos estudos elevantamentos históricos, é a exclusão que se destaca como algo que ocorre de modo mais evidente, recorrente e contrastante.

A análise que privilegia a exclusão das mulheres da cidadania focou as barreiras institucionais e estruturais para o seu acesso à cidadania democratica, ou a hipótese patriarcal. Tal hipótese, segundo Siim (2000), teria, nos trabalhos de Carole Pateman, uma importante expressão a explicar a exclusão das mulheres da cidadania e sua inclusão específica como mães, como resultado da divisão moderna entre público e privado. Mas exclusão não implica, apenas, explicitação formal e procedimentos legais. Implica uma dimensão subjetiva e cultural que estrutura e constrange as capacidades de escolhas (Bourdieu, 1989). De fato, esse trabalho de registro e de visibilidade da ausência foi e tem sido essencial para a demanda por presença. Contudo, 
em muitas ocasiões, identifica-se um efeito indesejado, o do receio da participação e da inserção no Estado e nos espaços institucionais, uma ação fundamentalmente defensiva. ${ }^{9}$

Novos problemas de exclusão conectados com educação, desemprego e marginalizacão do mercado de trabalho apontaram novos desafios para as abordagens da cidadania no início da década de 2000 (Siim, 2000; Young, 1990; Lister, 2003; Yuval, 1997). Entre outos aspectos, os estudos procuraram integrar diversidade e diferença baseadas em gênero, etnicidade e raça nos modelos da cidadania. Procuraram também traçar a conexão entre seus aspectos sociais e políticos.

Em balanço geral das abordagens, aponta-se para um repensar feminista sobre cidadania, calcado no restabelecimento do vínculo entre direitos sociais das mulheres e a cidadania democrática. Tal articulação constituiria um dos legados da história do feminismo e um enfoque importante para as abordagens dos direitos sociais. Nesse deslocamento de foco, o centro não é mais a questão teórica do patriarcado e da exclusão feminina. É, sobretudo, o processo dinâmico da participacão das mulheres na sociedade civil e na vida politica (Lister, 2007; Siim, 2000).

Vê-se que, no caso das mulheres, assim como no de outros grupos sociais, exclusão como ação intencional que precede o desenho da democracia e inclusão como ação coletiva em torno da qual se demanda e se aspira participação são dois movimentos concomitantes. Ambos estão envolvidos na trajetória histórica e na capacidade de agência dos diferentes atores/atrizes da modernidade. O interesse na agência das mulheres e a inclusão nas instituições passam a ser bases importantes de demanda e de estudos. Primeiro, porque há a crença de que política importa. Segundo, porque se promove um link entre uma cidadania ativa e participatória e demandas por direitos e igualdade política e civil (Phillips, 1991; Lister, 2003). Por fim, o foco na agência das mulheres aponta para a importância das suas atividades como mães, trabalhadoras e ativistas e para a interconexão das diferentes arenas do estado, do mercado e da sociedade civil (Siim, 2000). Nesse sentido, mulheres não são só vítimas, mas constroem também suas formas de inserção moldadas por contextos e campos de forças.

Sobre isso ver, entre outros, alguns artigos sobre gênero e participação política, e gênero e estado em Krook e Childs (2010). 


\section{Dualidade de esferas: entre agência, confinamento ou interdependência}

Como já se mencionou, a cidadania remete à ideia de processo, à ação coletiva dos indivíduos. Mas, como um processo, cidadania é, também, a experiência vivida. Tal experiência, como prática, vincula-se de algum modo com a ideia de participação e de coletividade, ou de uma "sociedade mais ampla" (Oldified, apud Lister, 2003, p. 14). Então, outro componente para pensar o gênero na cidadania é a construção do sujeito a partir de suas experiências, nas suas dimensões sociais, coletivas e individuais. Isso porque, no modelo, há indivíduos autônomos, mas, ao mesmo tempo, cindidos, não só em direitos, mas na potencialidade de se constituirem a partir de suas experiências.

É sabido que a cidadania surge intrinsecamente vinculada à ideia de indivíduo, o que lhe confere um caráter inerentemente contraditório e tenso. Só é possível pensar em cidadania a partir de algum grau de abstração e de universalismo do sujeito. O cidadão é o indivíduo membro de uma coletividade, da cidade, da comunidade da nação a quem lhe é conferida soberania para tomar parte nas decisões. Mas a premissa da autonomia do indivíduo e sua cisão (implícita) numa separação de esferas são aspectos contraditórios.

Algumas perguntas propostas por Turner (1990) são esclarecedoras dessas contradições: que indivíduo autônomo é esse que se constrói previamente aos processos sociais, e cuja premissa definidora de sua existência é essa prévia autonomia desvinculada dos processos sociais? Como esse indivíduo maneja a organização da vida com base numa esfera - a pública - onde, como cidadão, pode se manifestar sobre assuntos de seu interesse, mas que, em outra esfera - a privada -,se depara com outro indivíduo (o feminino), que se constitui como não cidadão e é compulsoriamente associado/confinado a essa esfera? E como pode existir uma única humanidade - portanto, uma categoria de seres igualmente formados a partir de certas condições - da qual uma parte não possui essas condições para exercer, de modo equitativo, direitos de trânsito e decisão entre essas duas esferas, como foi, e ainda é, o caso das mulheres?

A dicotomia entre público e privado foi, portanto, aspecto que teve e tem vários impactos sobre as mulheres. Para que alguns pudessem ser livres e exercer a igualdade no trabalho e na política, outros necessitavam preservar esse lugar particular que sustentava o refazer do cotidiano - lugar, porém, 
que exigia um contrato, implícito, de sujeição de um sexo ao outro, mesmo que tal afirmação soe contraditória, já que contrato requer aquiescência de mais de uma parte apta a contratar ou definir. No caso em foco, as mulheres, uma das partes necessárias para que isso pudesse se realizar, não possuíam autonomia ou capacidade para fazer tais contratos (Pateman, 1989, 1990).

Com isso, pretende-se chamar atenção para outra implicação, para além da associada à esfera pública como exercício da política. Trata-se da cisão da democratização da vida cotidiana como dimensão essencial para os membros de uma coletividade seguirem na vida. Mas não apenas para prosseguirem na vida. Esse é outro ângulo, que vai além do seu status de privado igual à submissão e do público igual à autonomia do indivíduo. Hoje, a ideia de uma boa vida, como uma vida cotidiana digna e satisfatória, é parte do ideário da justiça democrática (Sen, 2009). Essa agenda tem tido nas mulheres um ponto importante de crítica não só em relação às suas próprias condições para prosseguirem na vida, mas como parte dessa perspectiva de justiça, talvez e inclusive porque elas enfrentem problemas nas duas esferas. Foram pensadas e tiveram suas vidas reguladas a partir da sua natureza passiva como indivíduos inaptos para a vida pública e adaptados para a vida privada. Mas, quando revertem tal modelo e constroem sua condição de ativas, e não mais passivas, como agentes e cidadãs, deparam-se com o problema efetivo de que a realização dessa condição não depende só delas. Como indivíduos, sua agência está inerentemente vinculada aos condicionamentos e obstáculos estruturais (Hayward e Lukes, 2008).

Não se trata só, portanto, de construir espaços na vida pública, mas sim de afirmar e dar visibilidade à dimensão básica e necessária da reprodução da vida. Várias práticas sociais inerentes ao convívio e à reprodução da vida social, em suas distintas dimensões, efetivamente não acontecem ou se realizam apenas por indivíduos isolados. Tampouco ocorrem só ou principalmente no âmbito da esfera pública. E aqui entram também o cuidado, os afetos, as necessidades básicas e as interações sociais não pragmáticas e/ou orientadas a fins econômicos ou políticos. Muitas dessas práticas têm como agentes efetivos as mulheres, não por sua natureza ou condição inerentemente altruísta, mas por uma trajetória histórica e situações compulsórias.

Postas as coisas em outros termos, é pensar que, ao lado dos marcos político-ideológicos de transformações de estruturas socioeconômicas, há outros modos vinculados às formas de conceber os caminhos por meio dos quais se 
realiza a agência humana. Assim, a agência como ação e a cidadania como princípio e direito teriam que abarcar simultaneamente tais dimensões. Como sair, então, de um modelo excludente e dual sem necessariamente descartar alguns de seus constructos? Algumas autoras apresentam como saída o que seria uma reformulação do princípio de autonomia desse sujeito. Elas reconhecem que o debate feminista sobre cidadania gera tensões, quando se trata de pensar o modelo inclusivo de democracia: incorporá-lo ao que já existe ou redesenhar essa democracia? Com base na igualdade ou na diferença? Relacional ou individualista? Ou ainda, considerando a invisibilidade de certas dimensões da reprodução, orientando-se por uma ética do cuidado ou por uma ética de justiça? Ao valor da autonomia como independência ou da interdependência?

Há claramente impasses e dificuldades em torno dessas perguntas. As demandas por cidadania têm, de certa forma, refletido o que Lister (2003) define como o debate entre um feminismo relacional e um feminismo individualista (não no sentido pejorativo, mas teórico). O primeiro pensa os direitos das mulheres como mulheres, e termina pondo ênfase nos valores do cuidado humano. E o segundo poria a ênfase nos direitos das mulheres como indivíduos, e o foco cairia sobre os direitos e demandas relacionadas com a independência pessoal. Como evitar tal dualidade, já que ambos compõem a existência e a definição do sujeito feminino?

A configuração societária assentada nessa ordem estruturou o próprio sistema de produção e reprodução da vida, tornando-a inerentemente tensa, já que os três pilares - direitos, autonomia de sujeitos e autonomia de vida privada - tornam-se o ethos moderno. Ao mesmo tempo, a dinâmica e o que ocorre na esfera pública dependem dessa outra dimensão. Mas a esfera privada, embora necessária, mesmo imprescindível, tende a se formar e a ser pensada com um repertório de características e atributos que "atrapalham" a cidadania. Nesse sentido, pode-se dizer que esse parâmetro de separação de esferas, que sustentou o modelo democrático, é inerentemente antidemocrático. Assim, um dos desafios à democracia contemporânea seria rearticular as duas dimensões que compõem a vida social.

Por fim, um dos últimos propósitos desta análise é introduzir uma proposta analítica apresentada por Lister (2003). Trata-se de um exercício para rearticular as esferas da vida e redefinir seu estatuto político, preservando a cidadania como chave. Sua crença é a de que é possível resgatar a ideia de 
cidadania introduzindo uma dimensão que articula o indivíduo ao coletivo. Sua proposta para resolver esse impasse é a interconexão entre algumas categorias. Segundo a autora, há uma antinomia nesse duplo movimento; antinomia essa possível de ser repensada a partir da ideia de interdependência relacional. O objetivo é evitar essa tensão ou mesmo superar a dualidade indivíduo autônomo / sujeito opaco e coletivo. Esse plano de análise não necessariamente inclui a temática do pertencimento por grupos, ou seja, o caso no qual o sujeito tem como requisito identitário de agente político a identidade de grupo ou só se faz presente a partir de um pertencimento comunitário específico. Antes mesmo de sua manifestação política, trata-se de pensar a sua dimensão sociológica ou a relação entre agência humana e autonomia.

Seria, portanto, uma articulação entre autonomia, dependência, interdependência e independência. Tal articulação tende a ser secundária ou invisível em muitos dos debates sobre cidadania, direitos e esfera pública. Primeiro, a autonomia é algo concebido como condicionado por e promovido na intercessão entre o público e o privado. Segundo, haveria que considerar duas premissas básicas: i) as demandas por autonomia das mulheres e a independência econômica são essenciais para a democracia; e ii) é necessário rejeitar o que seria uma falsa dicotomia entre dependência e independência, em favor de noções mais amplas de interdependência. Essa saída seria, também, uma alternativa semântica ao fato inescapável da interdependência humana (Fraser e Gordon apud Lister, 2003). Tal proposição permitiria, segundo Lister (2003), revalorizar o lado desvalorizado da dicotomia público-privado, ou seja, reabilitar a dependência como qualidade humana normal e mesmo valorosa.

Nesse sentido, como alternativa à autonomia concebida em termos mais individuais, se proporia a autonomia relacional. Nesta, um self autônomo não seria construído no oposto à ideia de dependência, mas na interdependência inerente à condição humana. Cidadania diz respeito à efetiva realização dessa condição relacional. A autonomia relacional pode, portanto, cumprir um papel interessante de mediação entre a crítica da cidadania liberal centrada no indivíduo como sujeito atomizado e as leituras mais coletivistas nas quais o sujeito termina subsumido nas estruturas. Isso é válido para todas as dimensões, incluindo a cidadania social como sua expressão. Mas parece particularmente importante nos campos políticos no que envolve o político e em como se tem acesso ou se chega a ele. 
Essa perspectiva permitiria evidenciar a dicotomia entre a(s) forma(s) de autonomia(s) segundo a perspectiva de gênero. Em geral, a interdependência humana e a dimensão relacional do sujeito masculino tendem a se apresentarem, de início, como inexistentes. Autonomia é problema para mulheres. Está relacionada com seu descolamento de um sujeito para o outro. Por isso mesmo, é contraditória e problemática quando posta aos homens nessa ideia de interdependência humana, a não ser quando introduzimos claramente a análise de classe.

A proposta surge então como mais um ponto para reflexão geral, pois permite pensar a cidadania como prática e como reivindicação democrática que incorpora aspectos hoje demandados sobretudo pelas mulheres e relacionados com a dimensão de uma boa vida cotidiana. Mas extrapola tanto o sujeito que demanda como o campo em relação ao qual se demanda como campo secundário e isolado na vida. Com isso, as formulações em torno dos direitos e da cidadania das mulheres que hoje tentam incluir a dimensão dos cuidados podem ampliar seu estatuto. ${ }^{10} \mathrm{E}$ podem ainda contornar a formulação maternal ou diferencialista com a qual tendem a ser associadas.

Assim, a interdependência humana permitiria tanto preservar a autonomia como também as necessidades coletivas, sem necessariamente se refletir numa dualidade ou se privilegiar o âmbito da esfera privada ou da esfera pública. Poderia ser pensada como um caminho alternativo ou mediador para a dualidade de dimensões de vida. Essa dualidade oferece um estatuto diferenciado no qual as mulheres não têm muita escapatória, a não ser afirmar seu vínculo inerente e particular, mesmo que com maior trânsito nos espaços existentes.

\section{Considerações finais}

Pode-se dizer que a abrangência e o significado que o termo cidadania adquiriu contemporaneamente são tanto devedores da crítica de seus limites como da ação e da luta feminista por direitos iguais. E isso, sem dúvida,

\footnotetext{
${ }^{0}$ Merecem registro, ainda, as críticas feministas a um dos principais pensadores e formuladores teóricos sobre a cidadania no século XX: Marshall (1950). Para muitos autores feministas, sua análise reproduz a tendência ao tratamento binário e dicotômico, a ideia de uma esfera de cidadania que não passa pela articulação com o âmbito do privado (Voet, 1988; Siim, 2000; Lister, 2003; Lister et al., 2007) ou que, para as mulheres, tem que ser fundamentada pelo privado (Dietz, 1985). E aqui, cabe, portanto, uma pergunta, a título de reflexão com base na cena contemporânea: em que medida se pode pensar numa cidadania plena, em que o sexo de fato não interfira, se a dualidade de esferas permanece marcada pela hierarquia e dualidade sexual - mais ainda, marcada e dependente?
} 
contribuiu para que o ideário de direitos se tornasse o paradigma dominante na segunda metade do século XX. Mas a sua própria transformação traz em seu bojo novos estatutos e lida, a todo o tempo, com novas ou até então pouco evidentes tensões e antinomias. Sobre isso, algumas tensões ressaltadas podem ser retomadas aqui como sistematizações. Resumindo-as na sua articulação com a questão de gênero, pode-se dizer que elas desafiam as concepções de democracia e suas práticas: o problema das contradições que acompanham a formação do conceito, no âmbito do que o mobilizaria, de quem o exerce como direito e de como se viabilizaria. E foram, sobretudo, as mulheres que o criticaram e o usaram como demanda.

Deparamo-nos ainda com as tensões associadas ao conteúdo do termo cidadão, construído com base na separação rígida de esferas e com as tensões geradas por sua abstração como conceito a ser corporificado e a realidade empírica. Atualmente, defrontamos-nos também com um grau de diversidade social ainda mais complexo, a definir quem e onde se realiza a cidadania, ou seja, com os apelos às noções de universalismo, de imparcialidade e de bens comuns. Por fim, nos vemos diante da natureza das obrigações que isso implica, em contraposição ao ideário dos direitos e que tem impactos particulares e efetivos sobre as mulheres. Deparamo-nos também com um problema de fundo para a própria realização da cidadania: a concepção estreita do sentido do "político". O pensamento feminista tem feito esforços e apresentado algumas contribuições importantes para essa problemática.

Uma desigualdade da democracia parece ser, portanto, a desigualdade da dicotomia estruturada nas fronteiras do público e do privado. Outra diz respeito ao que é incorporado ou digno de compor ou ser reconhecido como político. As feministas ainda estão às voltas como essa problemática: o que é da esfera da política e o que é pessoal e pode ser realizado no âmbito do privado e da intimidade. Dois aspectos surgem como relevantes: compreender a participação com requisito e como processo de um ambiente que implica participação em esfera pública; e a capacidade de redefinir seus vínculos e a relevância da esfera privada. ${ }^{11}$

Dietz concebe a cidadania como algo "expressamente político", intrínseco à premissa participatória e democrática. Segundo ela, a "política envolve

1 Aqui merece referência o diálogo entre Hayward e Lukes (2008) sobre a relação entre poder, estruturas e agência humana, que surge como um instrumento analítico interessante para pensar essa trajetória das mulheres. 
engajamento participativo e coletivo dos cidadãos na determinação das questões de sua comunidade" (2007, p. 15). Nesse sentido, salienta que a participação política ativa deveria ser "valorizada como uma expressão da cidadania, em contraste com a concepção existente entre certas correntes feministas de concebê-la (a cidadania) como uma 'barreira de direitos"'. Já Pateman (1983) tenta formular tal fronteira com base em uma possível distinção entre o que seria vida política e os aspectos privados da vida social, não objeto de ação pública. Sobre o estatuto do público e do privado como dimensão social da vida privada, um bom exemplo nos é fornecido por Phillips (1991). Ela menciona a distinção entre campanhas públicas para os homens fazerem trabalho doméstico numa divisão justa, por um lado, e simplesmente a divisão de trabalho em sua própria casa. No primeiro caso, homens entrariam como cidadãos. No segundo, não.

A centralidade histórica da divisão público/privado para a exclusão e inviabilidade do próprio princípio democrático parece ser um dado. $\mathrm{O}$ terreno como locus da cidadania política seria o da coletividade de fato, a esfera pública. Mas isso não pode ser dissociado do que acontece no privado, o que define seus contornos e o que pode ser propriamente objeto da cidadania.

Alguns caminhos estão colocados para repensar a divisão público versus privado e a cidadania política, na medida em que esta permanece como princípio organizador e, ao mesmo tempo, contraditório. As barreiras práticas para as mulheres obterem plenamente ou redefinirem a cidadania reside na inter-relação entre público e privado, especialmente pela divisão sexual do trabalho e do tempo; e o que é esfera pública é algo mais amplo do que aquilo que tem predominando como pertencente à política formal.

Ao tratar como irrelevante para a cidadania (e eu diria, para a democracia) o que acontece na esfera privada, o discurso dominante constrói uma fronteira moral entre família e política. Tal fronteira permanece usada para justificar a não intervenção em injustiças ou opressões dentro da família e negar ou minimizar o significado do trabalho doméstico em relação ao qual o exercício público da cidadania é sempre dependente (Lister, 2003, p. 120).

Em suma, há uma miríade de novas questões e/ou a exacerbação de outras a serem repensadas. A diversidade e a ampliação das clivagens sociais e politicamente relevantes tornam a cidadania mais relevante, mas mais problemática - ou seja, do ponto de vista da cidadania, continua necessário observar como e compreender o porquê de a questão do gênero permanecer 
importante e interferindo desfavoravelmente na vida das mulheres. Nesse sentido, há também que considerar o fato de que a democracia hoje (na perspectiva processual) requer equidade entre pares - cidadãos - individuais e coletivos. Em suma, a crítica feminista é uma intermitente colaboradora da ampliação do ideário de cidadania como justiça e direitos e do escopo do político como essencial e abrangente para seguirmos na vida.

\section{Referências}

ARAÚJO, Clara M. de O. (1999). Cidadania incompleta: o impacto da lei de cotas sobre a representação política das mulheres no Brasil. Tese em Sociologia e Antropologia. Rio de Janeiro: UFRJ.

BENHABIB, Seyla (2004). The rights of others: aliens, residents and citizens. Cambridge: Cambridge University Press.

(2002). The claims of culture: equality and diversity in the global era. Princeton: Princeton University Press.

BOURDIEU, Pierre (1989). "A representação política. Elementos para uma teoria do campo político", em O poder simbólico. Lisboa: Difel.

COOLE, Diana H. (1988). Women in political theory: from ancient misogyny to contemporary feminism. Boulder: Lynne Rienner.

DIETZ, Mary G. (2007). "Political theory, feminist theory: an interview with Mary G. Dietz”. Gender: Dynamic, v. 18, n. 1, p 3.

(1985). "Citizenship with a feminist face: the problem with maternal thinking". Political Theory Today, v. 13, n. 1, p. 19-37.

DUBY, Georges \& PERROT, Michele (orgs.) (1994). História das mulheres. Livros 3, 4 e 5. Porto: Afrontamento.

FRASER, Nancy (1993). "Rethinking the public sphere: a contribution to the critique of actually existing democracy", em CALHOUN, Craig (ed.). Habermas and the public sphere. 5. ed. Cambridge: The MIT Press.

(2003). "Social Justice in the age of identity politics: redistribution, recognition, and participation", em FRASER, Nancy \& HONNETH, Axel. Redistribution or recognition?: a political-philosophical exchange. Londres, Nova York: Verso.

(2007). "Mapeando a imaginação feminista: da redistribuição ao reconhecimento e à representação". Revista Estudos Feministas, v. 15, n. 2, p. 291-308. 
\& GORDON, Linda (1994). "Dependency demystified: inscriptions of power in a keyword of the welfare state". Social Politics, v. 1, n. 1, p. 4-31. GOERTZ, Gary \& MAZUR, Amy G. (2008). Politics, gender and concepts: theory and methodology. Cambridge: Cambridge University Press.

HABERMAS, Jürgen (1987). Direito e democracia: entre facticidade e validade. 2. vol. Rio de Janeiro: Tempo Brasileiro.

HAYWARD, Clarissa R. \& LUKES, Steven M. (2008). "Nobody to shoot? Power, structure and agency: a dialogue". Journal of Power, v. 1, n. 1, p. 5-20.

ISIN, Engin \& Turner, Bryan S. (2007). "Investigating citizenship: an agenda for citizenship studies". Citizenship Studies, v. 11, n. 1, p. 5-17.

KROOK, Mona L. \& CHILDS, Sara (2010). Women, gender and politics: a reader. Oxford: Oxford University Press.

LISTER, Ruth (2003). Citizenship feminist perspectives. 2 ed. London: Palgrave McMillan.

et al. (2007). Gendering citizenship in Western Europe: new challenges for citizenship research in a cross-national context. Bristol: The Policy Press.

MAGNETTE, Paul (2005). Citizenship: the history of an idea. Colchester: ECPR Press.

MARSHALL, Thomas H. (1950). Citizenship and social class and other essays. Cambridge: Cambridge University Press.

MATLAND, Richard E. (2002). "Estrategias para ampliar la participación femenina en el parlamento. El proceso de selección de candidatos legislativos y los sistemas electorales", em MÉNDEZ-MONTALVO, Myriam \& BALLINGTON, Julie (coords.). Mujeres en el parlamento: más allá de los números. Estocolmo: IDEA.

PATEMAN, Carole (1983). "Feminist critics of the public-private dichotomy", em STANLEY, Benn \& GAUS, Gerald (eds.). The public and the private in social life. London: Croom Helm.

(1985). The problem of political obligation: a critique of liberal theory. 2. ed. Berkeley: University of California Press.

(1989). O contrato sexual. Rio de Janeiro: Paz e Terra.

(1990). The disorder of women: democracy, feminism and political theory. Stanford: Stanford University Press. 
PAXTON, Pamela M. (2008). "Gendering democracy”, em GOERTZ, Gary \& MAZUR, Amy (eds.). Politics, gender and concept: theory and methodology. Cambridge: Cambridge University Press.

PHILLIPS, Anne (1991). Engendering democracy. Pennsylvania: Pennsylvania State University Press.

RIOT-SARCEY, Michèle (1995). Democratié et representation. Paris: Kime. (2006). Histoire du féminisme. 2. ed. Paris: La Découverte.

(2009). "Poder(es)", em HIRATA, Helena et al. (orgs.). Dicionário crítico do feminismo. São Paulo: Ed. UNESP.

ROSANVALLON, Pierre (2010). Por uma história do político. São Paulo: Alameda.

SEN, Amartya (2009). A ideia de justiça. São Paulo: Companhia das Letras. SIIM, Birte (2000). Gender and citizenship: politics and agency in France, Britain and Denmark. Cambridge: Cambridge University Press.

THERBORN, Göran (2006). Sexo e poder: a família no mundo, 1900-2000. São Paulo: Contexto.

TURNER, Bryan S. (1986). Citizenship and capitalism: the debate over reformism. London: Unwin Hyman.

(1990). "Outline of a theory of citizenship". The Journal of the British Sociological Association, v. 24, n. 2. p 189-217.

(2001). "The erosion of citizenship". British Journal of Sociology, v. 52, n. 2. p 189-210.

(2006). Vulnerability and human rights. Pennsylvania: Pennsylvania State University Press.

URBINATI, Nadia (2006). Representative democracy: principles and genealogy. Chicago: University of Chicago.

VOET, Rian (1998). Feminism and citizenship. London: Sage.

YOUNG, Iris M. (1990). Justice and the politics of difference. Princeton: Princeton University Press.

YUVAL-DAVIS, Nira (1997). Gender and nation. Londres: Sage.

\section{Resumo:}

O objetivo do artigo é discutir a relação entre cidadania, gênero e democracia. Os focos são as trajetórias e as dimensões política e teórica da cidadania que constituem e atravessam a modernidade como um valor generificado. Essas trajetórias, por sua vez, geram 
diversos tipos de questionamentos e críticas. A cidadania se equilibra, assim, entre um passado enviesado e um presente aclamado, porém, tensionado quanto à igualdade entre homens e mulheres. Não parece ser o caso, contudo, de descartá-la, e, sim, de pensar as possibilidades de superar seu viés excludente de gênero e, ao mesmo tempo, reincorporá-lo como referência de equidade e parte desse ideário. $O$ texto se estrutura da seguinte maneira: preliminarmente, são feitas algumas considerações gerais sobre categorias que se articulam e se fazem presentes na democracia contemporânea; em seguida, são apresentadas algumas das incongruências constitutivas do sujeito-ator-cidadão, quando pensadas na perspectiva de gênero e, sobretudo, no seu pressuposto de se viabilizar como recurso legítimo da democracia representativa. Com isso, a intenção é retomar e refletir teoricamente sobre algumas tensões constitutivas da cidadania, sobretudo quando esta é analisada na perspectiva de gênero e, ao mesmo tempo, indicar possíveis saídas analíticas e caminhos de preservação discutidos pela literatura.

Palavras-chave: gênero; cidadania; democracia; representação política; direitos.

\section{Abstract:}

The aim of this paper is to discuss the relationship between Citizenship, Gender and Democracy. The focus is on the trajectories and political and theoretical dimensions of Citizenship that crossed the modernity as gendered value. This trajectory, in turn, generates various types of questions and criticism. Citizenship balances thus between a biased past and a tense present. There not seems to be the case, however, to dismiss it, but to think of the possibilities to overcome their gender bias, while this perspective can be reincorporated as part of its values. The text structures as follows: it presents some preliminary considerations about general political categories that articulate and are present in contemporary democracy. Following, discusses some incongruities that constitute the subject/actor citizen, when designed in a gender perspective, and especially in its assumption that feasible as a legitimate feature of Representative Democracy. With this intention is to reflect theoretically on some constitutive tensions of citizenship when it is analyzed from a gender perspective, at the same time trying to indicate possible analytical outputs discussed by the literature.

Key-words: gender and rights; citizenship; democracy; political representation.

Recebido em 2 de junho de 2012.

Aprovado em 2 de setembro de 2012. 